\title{
Mini-Grid Data Storage and Management Cloud Computing for Smartgrid Architecture, Apply in Ecuador Electrical Network
}

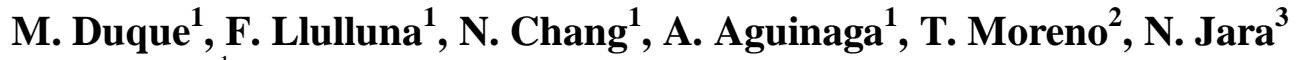 \\ ${ }^{1}$ Escuela Politécnica Nacional University of Technology \\ Ladrón de Guevara, Quito, Ecuador \\ mauricio.duque@epn.edu.ec; fredy.llulluna@epn.edu.ec; nikolas.chang@enp.edu.ec; alvaro.aguinaga@epn.edu.ec; \\ ${ }^{2}$ Escuela Superior Politécnica del Chimborazo \\ Panamericana Sur km 11/2, Riobamba, Ecuador \\ telmomoreno@hotmail.com; \\ ${ }^{3}$ Universidad Politécnica Salesiana \\ njara@ups.edu.ec
}

\begin{abstract}
In this paper, we pretend to create a logical way to managed a mini-grid and micro-grid architecture that can be implemented in Ecuador Electrical Network; this architecture will allow to increase the electrical efficiency. In Ecuador, 70\% of the electricity is not harnessed for multiple reasons, between them, the long distances for distribution and also because all electrical network is unidirectional. We are working to obtain the maximum advantage by creating a stable and hold architecture by using the internet of things and Smart Grid topology. Each Mini-grid can generate, produce and transmit energy toward hard demand places. Many countries join efforts to produce many smart-grid standards, but we are researching to change this target, the main goal is the mini-grid and microgrid approach, for this way, we can transform many homes in an electrical mini-generators which can allow electricity to inject in a network; reducing losses, increasing the efficiency to redirect the electricity for needy places without modify the current network and leave out the services provider. To achieve these goals, all electronic devices of the house must be connected to the internet and managed through a self-sufficient cloud APP. Can you imagine just one house with solar panels in the roof, wind generators and other devices that can generate electricity, and inside the home, all things interconnected between themselves (i.e. TV, Microwave, heating system, opening and closing doors, dishwasher, washing machine, lights and so on) all this functions we will manage through the web APP, which can enable and disable each devices or can redirect the energy remainder outside the home; reducing losses for stock and transmission the energy, that is usually expensive and profitless.
\end{abstract}

Keywords: Smart grid, Mini-grid, Electrical Network, Efficient Energy, Internet of Things.

\section{Introduction}

In Ecuador is trying to change the productive matrix through implement different strategies, between these we have eight hydroelectric project and one Aeolian project, all these executed in the last 8 years. The actual government thinks that the best way to change the matrix is by generating electricity projects but this is not true because the main problem is the poor electricity efficient, even worse, the high cost for these programs, for example 1,500 MW of Coca-Codo Sinclair Megaproject rises to \$1.68 USD billions, however, specialists are warning that due to inadequate planning and an inflated design the project will be an ecological disaster and won't deliver its promised energy production. "So basically you have the first country in the world that legally respects nature, and they are about to destroy their greatest waterfall," said Dr. Matt Finer of the DC-based Save America's Forests. "While we applaud and support Ecuador's revolutionary initiative to leave oil reserves under the Amazon, this hydroelectric project is just a step back to business as usual."

According to Matthew Terry of the Napo River Foundation, located in Tena-Ecuador, the principal problem is that the project is completely over-dimensioned in relation to the amount of available flow in the river, and lacks a comprehensive environmental impact study as well as a number of technical studies, final designs and a definitive budget just to show an example. All the analysis for this catastrophe you can look up in the report "Ecuador's most spectacular waterfall threatened by Chinese-funded hydroelectric project" by International Rivers Protection [1]. 
Without speaking of the other seven projects that are in the same state of affairs, the government arrangement was selling electricity for another countries except infeasibility cause for the high budget that in the end it will not be competitive. If all the inversion disposed for the electric structure will be use to implant a Smart-grid architecture the income will be more.

For that's reason we present above the best way to create a Smart-grid to start for the micro-gird and mini-grid architecture, in Ecuador or any country, by implementing accessible and independent components for electrical topology with low cost.

Some countries are developing different concepts about Smart Grid topology but in Ecuador community work have being done to implement these systems that are require urgently to optimize the present grids of the country, primarily for environment lower emissions, to avoid the dependence on oil, to increase the profitability and improve the electrical system as we shall see there are many adverse situations that prevent the implementation of these systems, so each device can decide when start/stop process themselves but managed across the web APP.

Ecuador has initiated a transformation process model from being an exporter of raw material to become a society that will export products based on knowledge and biodiversity. By the changing of the productive matrix, Ecuador will provide products with high added value, according to the government: Ecuador is betting to change its production model in a long term, where the change of imports and exports, along with innovation, science, technology and knowledge will allow to give a massive step in to the future.

Even though in Ecuador Smart-Grids systems could be implemented, this kind of technology is available the most of the time for first world countries, which have a bigger economic power than countries that have a poor economy. In the same way, business that owns this kind of technology will create technological dependency due to they are owners of the systems that also impose policies that are beneficial for their industry but not for the industrial development of the country.

What is a Microgrid and Mini-Grid?

A Micro-Grid is a local energy grid with control capability, which means it can disconnect from the traditional grid and operate autonomously.

Mini-Grid is smaller than a microgrid that allows each device that is connected to convert in smart device; each connected like a net that use internet via, the main propose is to control any variable on the smart home and join all the Smart Grid; each device reports any event to web APP and it controls all net by creating independent behavior like an organism as a colony where each particle collaborate for a specific function and together improve the throwput electric network.

The grid can connect to houses, businesses and other buildings to central power sources, which allows us to use appliances, heating/cooling systems and electronics but this interconnectedness means that when part of the grid needs to be repaired, everyone will not be affected. This is where a microgrid can help.

A microgrid generally operates while is connected to the grid but the most important thing, it can break off and operate on its own by using local energy generation in times of crisis like storms or power outages or other reasons; the most important idea, is in the moment when the mini-grid do not required energy this can be inject and redirect through the network to places that need it the most bypassing battery cells use, but this is not common to happened.

A microgrid can be power by distributed generators, batteries, and/or renewable resources like solar panels depending on how it's fueled and how the requirements are managed; a microgrid might run indefinitely while it has favorable conditions.

\section{Some achievements for the Smart Grid on a world:}

- Thousands of interconnected energy plants, that's advantage for directional way and redirect energy flow.

- Better in a entry qualities.

- CAIDI: Average Interruption Time.

- MAIFI: average interruption frequency index.

- Automation Maximize.

- Better network efficiency.

- Reducing the environmental impact of electrical system. 
These achievements a milestone for advantage and efficient energy because it is time to advance and rethink the most common energy topology and uses.

\section{Overcome barriers:}

Generation, Transmission and Distribution are businesses that according to the law must be separated from the main companies. Generation produces energy, for that reason energy has to be sold; transmission carries all the energy and distribution sell's the most of the product with the less inversion; consequently, all these services providers do not care about the quality of energy or network losses, these all its product of politics the globalization and capitalist, if many enterprises can see than more yours eyes and personal interest, may be together can transform and correct the way, and finally implements the Smart Grid uses.

Why is Smart-Grid viable to be implement in Ecuador?

Because Ecuador has the conventional electric topology and the government do not do anything to modernize it; this have created a problem and leaded to have many questions: Which is the best philosophy and topology? This questions leads us to the conclusion that each method (philosophy and topology) is different; for example: EEUU, has identify 75 kinds to transform the actual networks through the NIST institute; Japan put all efforts to reduce dioxide carbon emissions by optimizing the combustion of engine cars and also by implementing electric Smart-Car; and Europe, European Committee for standardization, (CEN), European Committee for Electro Technical standardization (CENELEC) and European Telecommunications Standards Institute (ETSI), have at least identify 110 kinds of the most important ways to open a source architecture for measure electricity.

Ecuador needs the best option for actualize this topology, innovate, develop, and change the productive matrix by implementing low cost plans to have benefits and an open source technology. If Ecuador is successful in the matrix changing, it will bring the opportunity for others countries that are same situation to change too.

\section{Research Questions}

I. What is the best cloud server to manage this APP?

II. What is the best data storage engine for save all the income information the mini-grid?

III. Is it possible to create a web APP that will be able to drive this topology?

\section{Objective}

To Find to the optimal way for create an APP that can approach this proposals by low cost components and OpenSource software and hardware; this topology and system will be built in Ecuador to contribute to change of the productive matrix, industrial energy optimization and decrease the losses in the electrical network.

\section{Specific Objectives}

I. To design a web APP managed architecture by cloud computing, draw upon the Internet uses and internet of things.

II. To mention a overall perspective in Ecuador about Smart-Grid refer to cloud app.

III. To describe the normally operation for the APP.

\section{Methodology}

We are researching for new structures to implement smart-grid topology, the principal target its to create an Smart Grid architecture support based on the web application for that reason, we propose a different structure to obtain this goal and the principal manager application can be hosted on cloud services, for example Amazon Web Services, Windows Azure or Heroku (is not my intention to sponsored brands), but in this moment they are the main cloud architecture that can be hold on APP because the big data processing income and outcome; due to this we suggest to use NodeJS server that can drive and support all data traffic.

\subsection{Topology}

Imagine an automation home, each device has a mini server embedded and connecting internet via; the APP receive all information to many devices, which indicate "start, stop, torn on, or turn off, injection or consumption" and so on, all this signals can be configured on the APP are settings depending of the user preferences. The APP can be managed from 
each Smart Home to optimize the energy consumption and if is possible to generate energy. The APP should carry the energy drive to another home that needs it, due to it the APP can improve the energy efficiently.

\subsection{Consider Tips:}

The Mini-Grid has different types of the devices, those who play (Actuators), and others that receive the signals (Sensors), in some cases one device can be have together functions (act and receive signals), see Fig. 1; in another hand we have devices that can inject electricity like a solar panels and fuel cells.
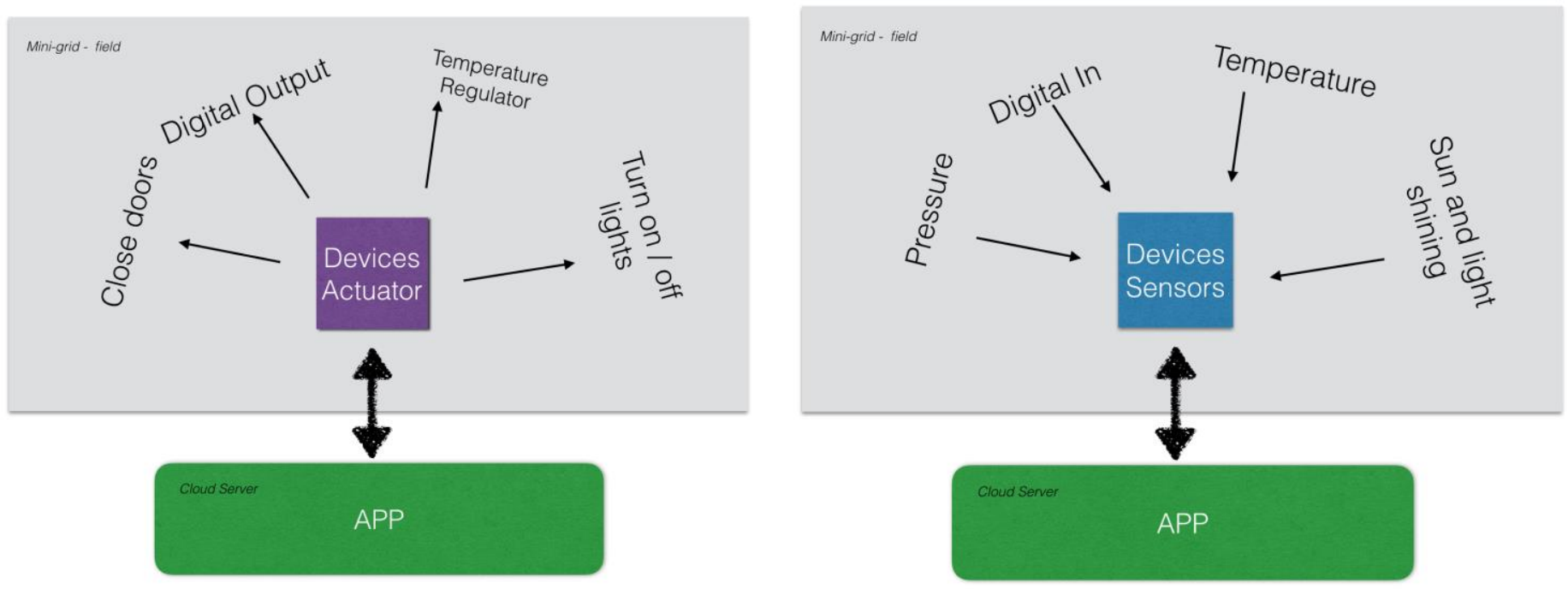

Fig. 1: Devices topology.

Each device has three functions: Manual, Automatic and Managed through the APP.

- Manual: the user can enable or disable the device, proceed to execute a function or not.

- Automatic: every functions was setting before, appears the autonomous way, the device capture the main signal to monitor and response according to the case.

- Managed through the APP: each device send data to APP, according the situation this process can evaluate what is the mini-grid that needs more energy, then this device proved the energy that other generates; this global function in a particular way, see Fig. 2, the APP can control independently every device in a Mini-Grid by managed and reported setups.

The Sensor devices capture the physical variable, convert it into digital, filtering, and scale variable, when the signal is clear and better, this will be transmitted by internet to the APP, next it will evaluate each Mini-Grids requirement and then will proceed to redirect energy flow or activate / inactivate but the main proposal is to increase electrical exploitation by driving the actuator devices.

\subsection{APP Structure}

Our structure is based on NodeJS server, because it is the most popular server nowadays and this allows to support over 64000 simultaneously connections and our asynchronous architecture can create real time applications; this is excellent for our design, moreover it has many modules which enables to customize and optimize the app. All NodeJS power from the V8 engine, develop for Google Chrome team.

\subsubsection{Data Base}

All data storage is supported by MongoDB database, it is the most popular non relational DB and it fits for our proposal, we pretend to create a document for each microgrid, in this way we can manage every device that is connected on the mini-grid. 


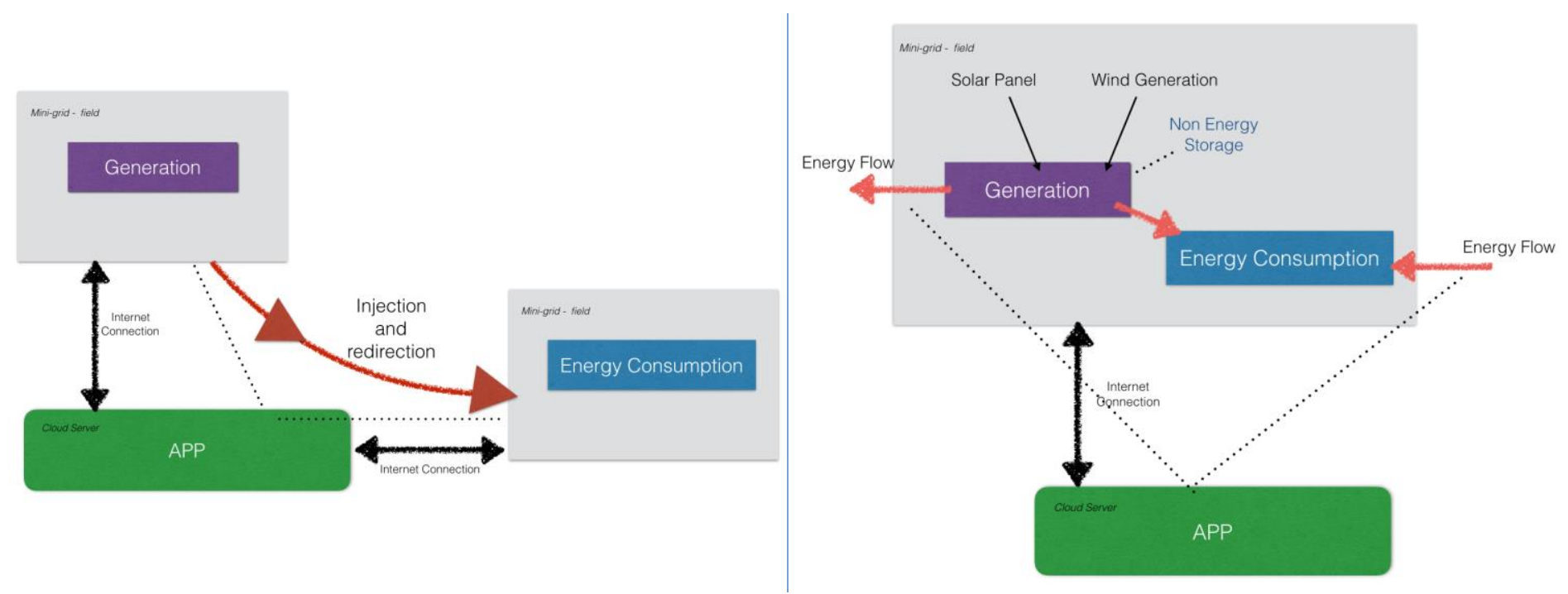

Fig. 2: APP Managed.

\subsubsection{Front-end Client side}

The APP is provided by desktop version by NW.JS packages, where each user can setup every mini-grid behavior, which can be access through any pc, tablet and smartphone, anyone OS, see Fig. 3.

NW.JS enable desktop version can convert a native application for every operative system. In the client side, the user can see each variable in a dashboard and customize every behavior for every device by App setups; although the App is hosted by CEDIA, the user can watch their devices and mini-grids, but the global behavior is control by the application.

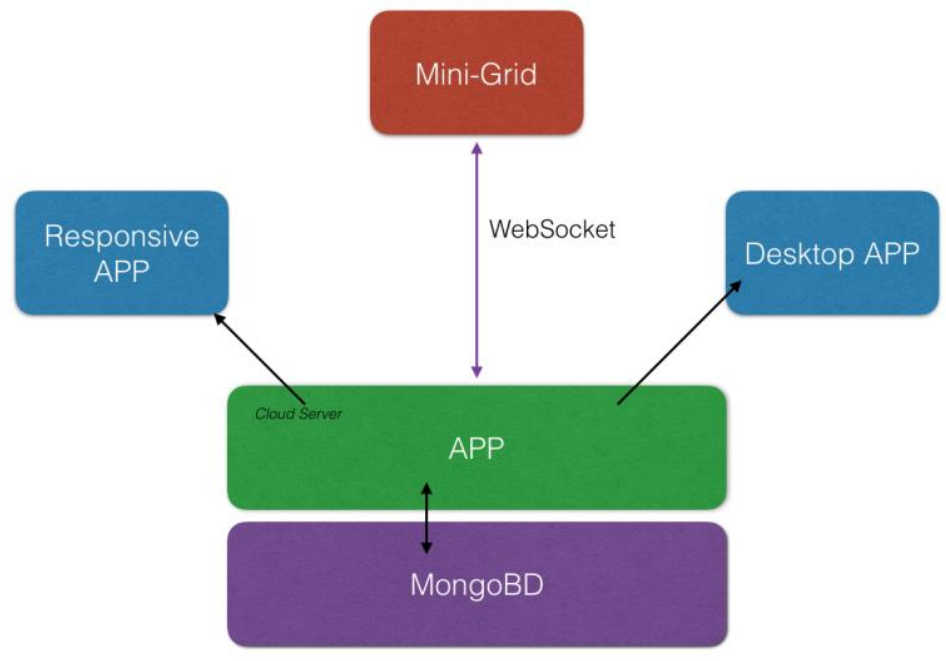

Fig. 3: App Structure.

Below, we describe all modules and components the APP have, see Fig. 4.

All the structure and code open-source project are hosted on GitHub repository: "https://github.com/SmartGridProject/smartgridproject", under MIT License and official project web page: http://smartgridproject.github.io/smartgridproject, and the download latest version: https://SmartGridProject.github.io 


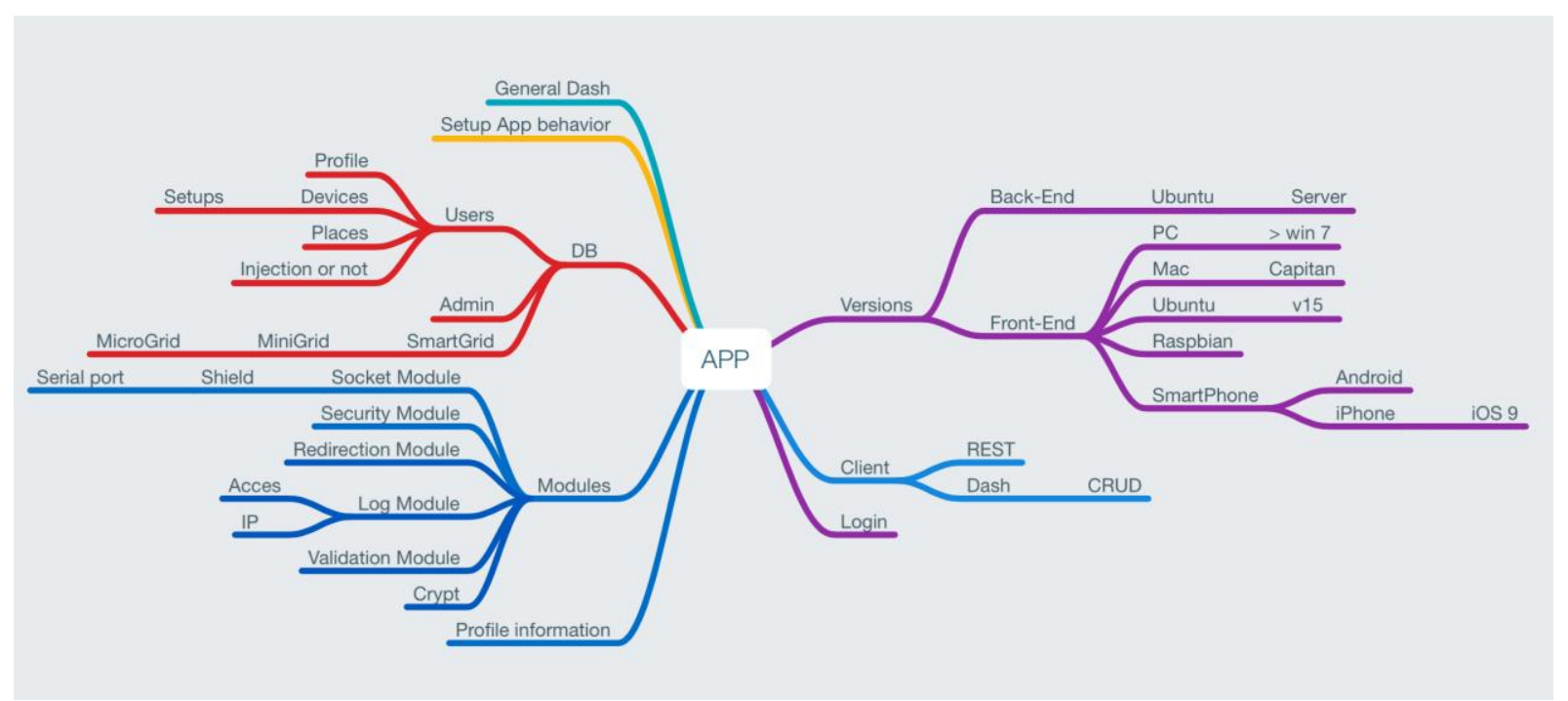

Fig. 4: App Modules and Components.

\section{Conclusion}

Through this document we support the research, and implement a prototype, which can be a lead on the Smart Grid cloud computing way, this structure allow many countries contribute to implement this architecture and consider the optimal way for manage the electrical network.

NodeJS is a powerful tool, this is the best way for build this app, and this is the future for the web applications, in real time that should replace the conventional native applications.

If the all countries implements this system or Smart Grids topology the electric exploitation will be losses decrease and improve the electrical efficient, due the build more and biggest electrics generations its not necessary so many billions can be harnessed to progress the Start Grid structure.

\section{Acknowledgements}

Our special regards to CEDIA, for to be sponsorship and financial support for this research.

\section{References}

[1] M. Terry and Napo River Foundation. Ecuador's most spectacular waterfall threatened by Chinese-funded hydroelectric project. [Online]. Available: https://www.internationalrivers.org/resources/ecuador-s-most-spectacularwaterfall-threatened-by-chinese-funded-hydroelectric-project.

[2] R. C. Rugeles and Acción pedagógica, "La instrumentación Virtual en la Enseñanza de la Ingeniería Electrónica," vol. $11, \mathrm{~N}^{\mathrm{o}} 1 / 2002$, pp. $74-84$.

[3] F. J. Quiles, J. I. Benavides, A. Moreno, R. Llamuza, J. C. Garcia, and M. A. Ortiz, "Unidad Docente Arquitectura de Ordenadores."

[4] EU. Politecnica, "Puesto De Instrumentación Virtual Digital," 14004 Cordoba.

[5] V. Congreso de la Sociedad Cubana de Bioingenieria, A. Adan Vidal, F. Fernández Pérez Terán, A. Calle Herranz, and E. Valdés Zaldivar. "Estrategia para una instrumentación virtual de bajo costo con aplicaciones médicas," Habana, 2003.

[6] G. León and A. Aguinaga, "Simulación de Control y Monitores Vehicular Usando Tecnología GSM Como Medio de Transmisión," Escuela Politécnica Nacional, 2011.

[7] C. Aguinaga Ávila, and E. Cando, "A Multi-layer based architecture for the development of an open source CAD/CAM integration virtual platform," in 3th International Conference on Mechanical Egineering and Mechatronics, ICMEM'14, Praga República Checa, 2014.

[8] J. Stamp, Sandia National Laboratories, "Microgrid Design Tools (MDT)," Smart Grid R\&D Program Peer Review Meeting, 2014. 
[9] Michael S., "Lawrence Berkeley National Laboratory," 2014 Smart Grid R\&D Program Peer Review Meeting. Oak Ridge, 2014.

[10] Department of energy, United States Of America, "The Future On The Grid, Envolving to Meet American's Needs,", No. GS-10F-0103J, 2014.

[11] U. S. Department of Energy Office of Electricity Delivery \& Energy Reliability, "Smart Grid Research \& Development, Multi-Year Program Plan (MYPP)," pp. 6 -22, 2012.

[12] Academia Journals, Lorandi, "Los Laboratorios Virtuales y Laboratorios Remotos en la Enseñanza de la Ingeniería," vol 4, 2011. 